\title{
Contribution to Citizenship of Tunisian Students during PSE Sessions
}

\author{
Mounira Ben Chaifa, Naila Bali \\ Doctor in Didactics of Physical Education, Tunisia \\ Email: mounirabenchaifa@gmail.com
}

How to cite this paper: Chaifa, M. B., \& Bali, N. (2020). Contribution to Citizenship of Tunisian Students during PSE Sessions. Advances in Physical Education, 10, 10-18. https://doi.org/10.4236/ape.2020.101002

Received: November 13, 2019

Accepted: December 15, 2019

Published: December 18, 2019

Copyright $\odot 2020$ by author(s) and Scientific Research Publishing Inc. This work is licensed under the Creative Commons Attribution International License (CC BY 4.0).

http://creativecommons.org/licenses/by/4.0/

\begin{abstract}
Many research and international reports have shown that civic education at the school corresponds to a strong societal need and that citizen knowledge is taken care of by school disciplines. This research aimed to verify the contribution of physical education and sport (PSE) to the citizenship of middle school students. The analyzes include Official Texts (OT) governing PSE and practices of PSE teachers. The results show that PSE is a school discipline that promotes student citizenship in two complementary modes; on the one hand, the use of physical and sports activities (PSA) that implicitly carry civic values; on the other hand, the direct intervention of the teacher who translates his values into action.
\end{abstract}

\section{Keywords}

Citizen Education, Official Texts, PSE, Citizen Value

\section{Introduction}

Many research and international reports have shown that civic education at the School corresponds to a strong societal need and that citizen knowledge is taken care of by school disciplines. According to Dugas (2002), although the school institution contributes to the education of future citizens, it is true that teachers are at the forefront of this education, the specific role of PSE in citizenship education.

Since the registration of sports physical education, in the school system, its objectives and missions have evolved, following the changes in the city. Recent official texts encourage the training of a student citizen, thus highlighting the usefulness of the discipline in the socio-political context. For Delignières (1999) "the PSE is plural". The author distinguishes three conceptions of PSE, according to the educational intentions of the teacher, namely the naturalistic, the cul- 
tural, and the citizen. The latter adopts the objective of training future citizens. The author takes as an argument to justify this citizen of PSE the use of reference practices as support in PSE. These practices represent a dense place of citizen expression in societies. The author asserts that the reference practices of the PSE are carriers of other techniques and norms, of citizen values. The problem of PSE is not to graft citizenship on its content, but to exploit the civic wealth of social practices that legitimize its presence in the school. Several authors (Andrew, Tessier, \& Bourgeault, 1997; Audigier, 2007; Delignières, 2015; Feyfant, 2010; Galichet, 2002; Heimberg, 2007) argue that it is not enough to pass to students a theoretical support explaining the values of citizens but, rather, to put it into action. According to Delignières (2015), citizenship education is not an automatic consequence of the practice of physical activity and sport; but, it must be "acted". Nowadays, PSE is socializing; we can integrate into PSE a big number of notions and values of citizenship. It would then be wise to question the practice of citizenship during PSE sessions and to see the type of citizen we encourage or train. The difficulty for PSE teachers is not to state the values of citizenship, but to translate them into their practices and to contribute to civic education during PSE sessions. The purpose of this research was to verify the contribution of the activity taught and didactic practices of PSE teachers to citizenship education. We are looking at two important points, namely the Official Texts governing PSE and the practices of PSE teachers. We wonder then whether the official texts governing PSE contribute to citizenship education in middle school and how do PSE teachers promote civic education during their practical sessions in college? And in the end, we looked for adequacy between the contribution to citizenship in the Official Texts governing PSE and the teaching practices in the college?

\section{Methodology}

To answer our questions, we began by analyzing the Official Texts governing the PSE. We conducted analyzes on the Official Instruction (IO) PSE, PSE curriculum for the middle school students, and recent PSE circulars. We established Analysis in the form of comparative tables of the percentages between the motor objectives and those of citizenship identify OT. On the other hand, we conducted analyzes with one hundred evaluation reports inspected at the colleges of governorates of Greater Tunis. We presented the results in the form of a comparative table of the percentages between the driving objectives and those of citizenships put forward by the inspectors. In a second step, we recorded and analyzed ten PSE sessions (including five group sports sessions and five individual sports sessions) led by ten PSE teachers practicing in different colleges of governorates of Greater Tunis. Each teacher is responsible for a mixed class of 34 plus or minus three students belonging to the middle school. We did not advise PSE teachers of the research objective to safeguard the reliability of the results. We have drawn up observation grids on the one hand, based on civic values derived from Official Texts, and on the other hand, on the nature of the activity (team sports, in- 
dividual sports), or the different parts of EPS lesson (getting started, setting up the body of the session and returning to calm), either on the way of treating the citizen value (treatment of the value explicitly or implicitly). We processed the data statistically by calculating the percentages $(\%=n \times 100 / N)$ and frequencies (character of what happens many times, of what happens at close intervals) of the data collected.

\section{Analysis of Official Texts Governing PSE}

\subsection{Analysis of Official Instructions and PSE Circulars}

To verify the type of objectives contained in the Official Instructions and circulars of the PSE, we subjected them to the percentage in the form of a table. The results are shown schematically in Figure 1.

\subsection{Analysis of Official PSE Programs Allocated to the Middle School}

To verify the type of objective contained in the Official PSE Programs allocated to the middle school, we submitted them to tabular analyzes. The results are shown schematically in Figure 2.

From Figure 1 and Figure 2, we note that the Official Instructions and PSE Circulars and Official PSE Programs allocated to the middle school, convey two types of objectives, namely motor objectives and citizenship objectives. The frequency of the motor objectives identified in the OT governing the PSE far exceeds that of the citizenship objectives.

\subsection{Analysis of Educational Evaluation Reports}

We analyzed the educational evaluation reports. We presented the results in the form of a comparative table of the percentages between the driving objectives and those of citizenship motivated by the inspectors.

From Figure 3 we note that PSE sessions address two types of goals, one motor and the other citizenship, and that the percentage of motor objectives (60\%) exceeds that of citizenship goals.

\section{Percentages of objectives identified at $1 O$ and PSE circulars}

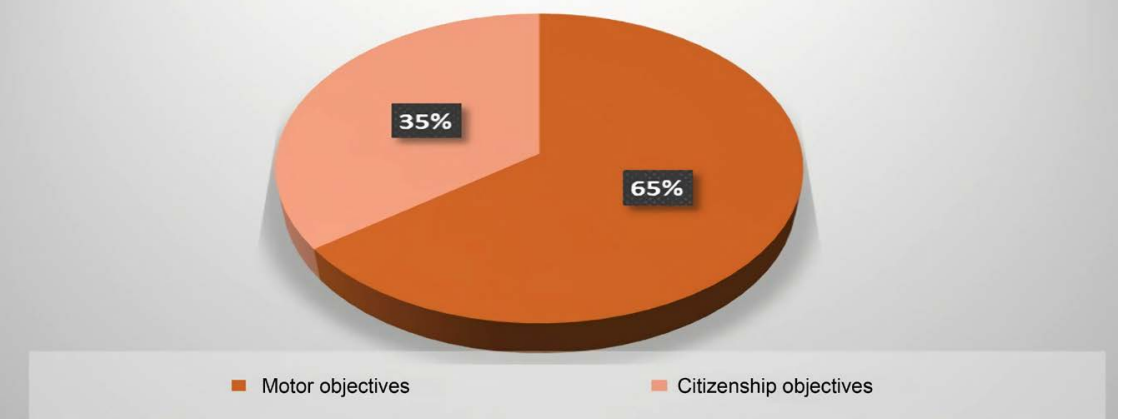

Figure 1. Percentages of objectives identified at OI and PSE circulars. 


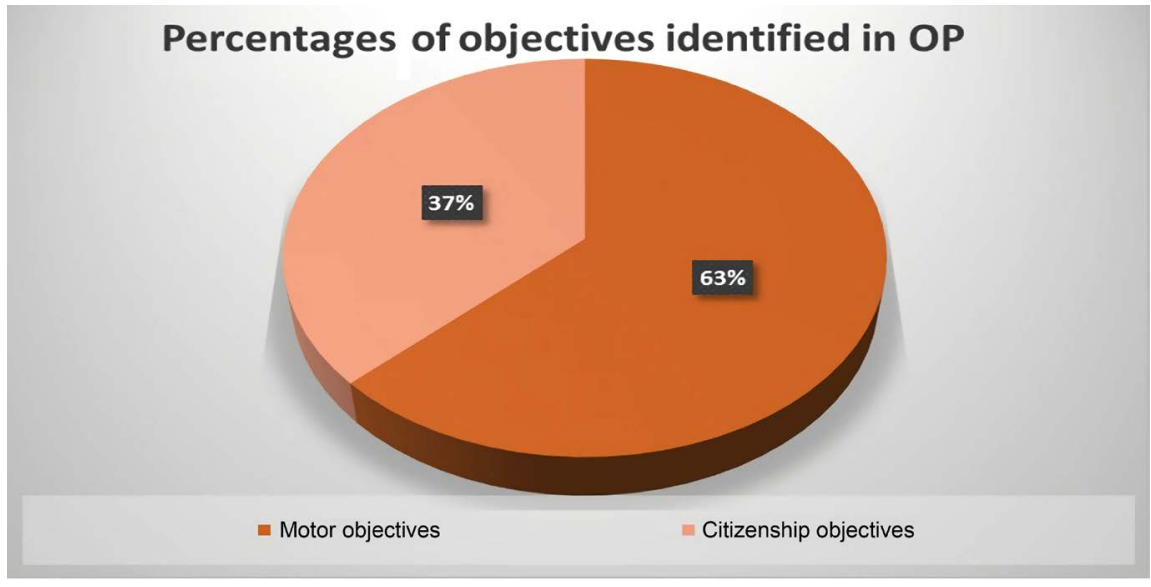

Figure 2. Percentages of objectives identified in official programs.

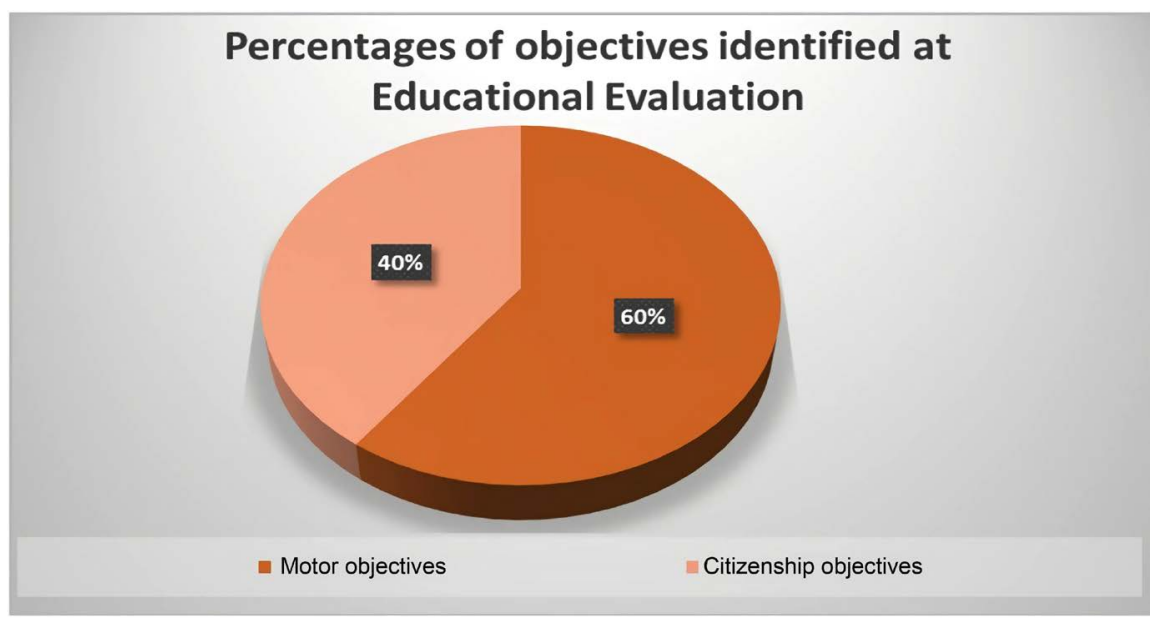

Figure 3. Percentages of objectives identified at educational evaluation.

We note that the Official Texts governing the PSE convey two types of objectives, namely one for motor purposes and the other for citizenship.

An examination of the comparative figures of the percentages of the goals identified in the OT shows us that the PSE sessions are based on exercises and motor learning situations that focus mainly on the learner's motor development. We confirm these results by the results of the analysis of the reports of the pedagogic evaluation.

\section{Analysis of Video Visualizations of PSE Sessions}

\subsection{Analysis Objectives during Practical EPS Sessions}

To verify the objectives conveyed by didactic practices of PSE teachers at the colleges, we analyzed the video visualizations of the ten PSE sessions; we summarized the results in Figure 4 as percentages of the motor and citizenship objectives identified during the practical sessions.

Figure 4 summarizes the percentages of the goals identified from the practical sessions of PSE we note that the practices of PSE teachers are based on two types 


\section{Percentages of objectives identified during practical PSE sessions}

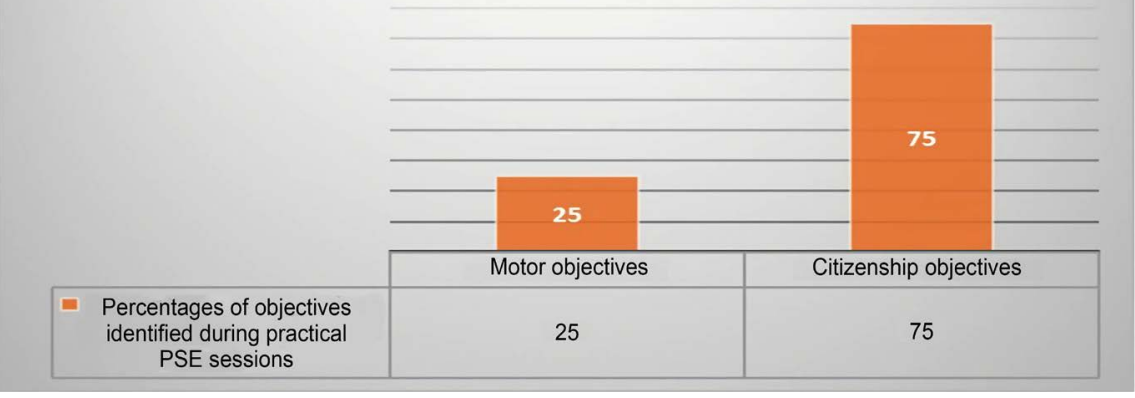

Figure 4. Percentage of objectives identified during practical EPS sessions.

of goals, namely, one motor and the other citizenship. And that the percentage of citizenship goals (75) identified in the instructional practices of PSE teachers exceeds that of the driving objectives (25). These results are logical because EPS teachers convey citizen values through motor learning situations and exercises. The latter implicitly carry one or more civic values at a time, let us add the interventions directly of PSE teachers.

On the other hand, we have noticed that motor objectives are dealt with in the course of three (or even two) PSE session sessions, namely start-up, the session body and the return to calm, or the civic values are treated throughout the lesson of PSE see even before, from the reception of students or inside the locker room. Thus, we note that the construction of PSE sessions deals with exercises and motor learning situations on which PSE teachers base their practices to convey the objectives of motor and citizenship.

Based on the results of the analyzes of the PSE sessions, we deduce that the practices of PSE teachers are based on two types of objectives, one of which is a driving force, the other of citizenship. Moreover, in the course of their didactical practice, PSE teachers focus mainly on the objectives of citizenship rather than on the motor objectives, contrary to what has been put forward in the course of the evaluation. In the light of these results, we affirm that there is no difference between the objectives conveyed by the Official Texts governing the PSE and those transmit by the practices of the teachers of PSE at the colleges.

\subsection{Influence of Nature of PSA on the Frequencies of the Objectives Treated during the Sessions of PSE}

To verify the impact of PSA on the use of the goals of the motor and those of the citizenship we compared the analysis results of the collective sports sessions (5 sessions) and those of the individual sports (5 sessions) (Figure 5).

The results show that the frequencies of the motor and citizenship objectives, treated during the individual sports sessions, slightly exceed those of the same goals, used in the course of the collective sports. This is because the lessons of the individual sports are based on learning situation of a socio-motor nature. In 


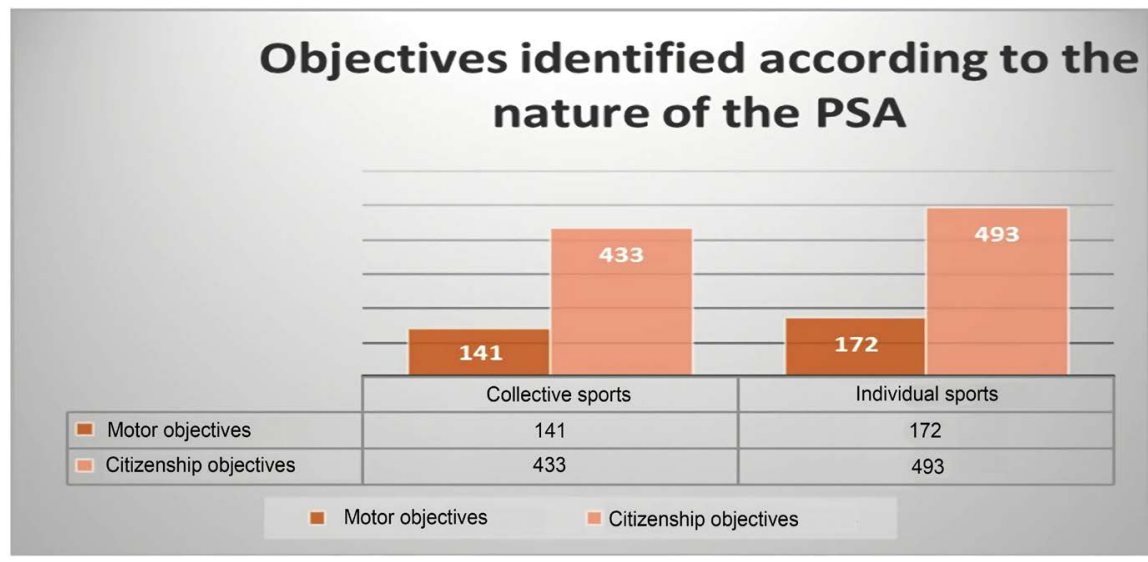

Figure 5. Frequencies of objectives identified during collective sports and individual sports sessions.

the latter case, student is in motor interaction with others. PSE teacher programs content in the form of fun games of competitiveness. Thus, with this choice, the educational approach and interventions, he can promote the treatment of the values of citizenship during the sessions of PSE. The treatment of citizenship objectives depends on the nature of the instructional content proposed in the PSE lesson.

\subsection{Influence of the Treatment Mode on the Frequencies of Citizens' Values}

To verify the impact of the treatment mode on the production frequencies of the citizen values during the PSE sessions we compared the results of those treated explicitly (formal and direct intervention of the teacher) and those used implicitly (the exercise or the motor learning situation is a carrier of value).

Figure 6 schematizes the frequencies of the citizen values according to their mode of treatment and according to the parts of the session of PSE. With the way of treatment of the citizen value we designated explicitly treatment of the value by the teacher or implicitly, the activity that carries the citizen value. With the different parts of a session of PSE we designated getting started, setting up the body of the session and returning to calm.

During grip, there is no treatment of social and civic values implicitly because there is no practice of PSA during this part of lesson PSE.

On the other hand, during the three parts of the lesson, where PSA is practiced, the frequency of explicitly treated citizens' values is lower than that of those treated implicitly. PSE teachers program motor learning situations that implicitly carry civic values, but during their practices, they do not insist explicitly of these values' treatment.

According to the comparison of the frequencies of production of the citizen values according to the different modes and according to the parts of sessions of PSE we deduce that the treatment of the citizen values depends on the way of their treatment (implicit, explicit). The teacher of PSE can contribute to the implicit 


\section{Civic values according to their treatment and according to the parts of PSE session}

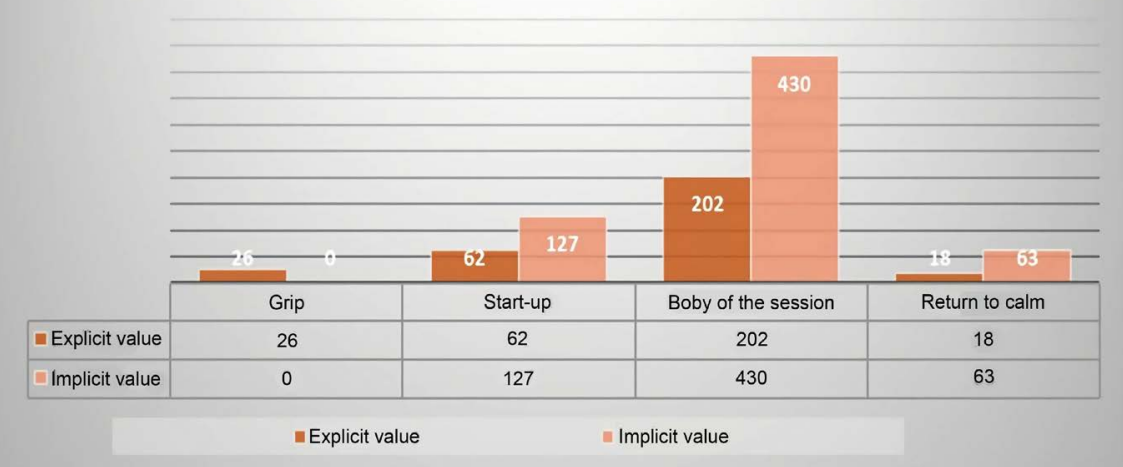

Figure 6. Frequencies of civic values according to their mode of treatment and according to the parts of PSE session.

treatment of the citizen values by choice of the PSA and the didactic situations (socio-motor situation), and encourages them to be explicitly informed by these interventions and the educational approach put into practice.

\subsection{Seating Part Influence on Percentages of Citizenship Objectives Addressed during Sessions}

To verify the impact of the nature of the parts of the session on the use of the motor objectives and those of citizenships we compared the frequencies of the different types of goals identified during the sessions of PSE according to these parts.

The results shown schematically in Figure 7 show that during the grip there is the complete absence of motor practice (0), but there is the treatment of citizen values in a low frequency (26). On the other hand, during the start-up, the motor objectives exceed those of citizenship. During this part of the session, motor learning is often done in the form of short and mostly individual motor learning exercises (Example: stretching exercise) apart from the fundamental objective of this part of the lesson (warming up of the body). During the main part of the session and the return to calm, the frequencies of the objectives of citizenship, exceed those of the objectives motor.

On the one hand, we also noticed that the frequency of the motor objectives identified during the start-up exceeds that of the motor objectives identified during the body of the session. We explain this that during the start-up, motor skills are based on short-term motor learning exercises that are often practiced individually. On the other hand, during the body of the session, motor learning takes the form of didactical situations that last over time and are practiced collectively. On the other hand, the frequency of citizen objectives increases as the frequency of the motor objectives (collective work) increases. Both types of objectives are closely related. Each part of PSE session has these own temporal and typical characteristics. 


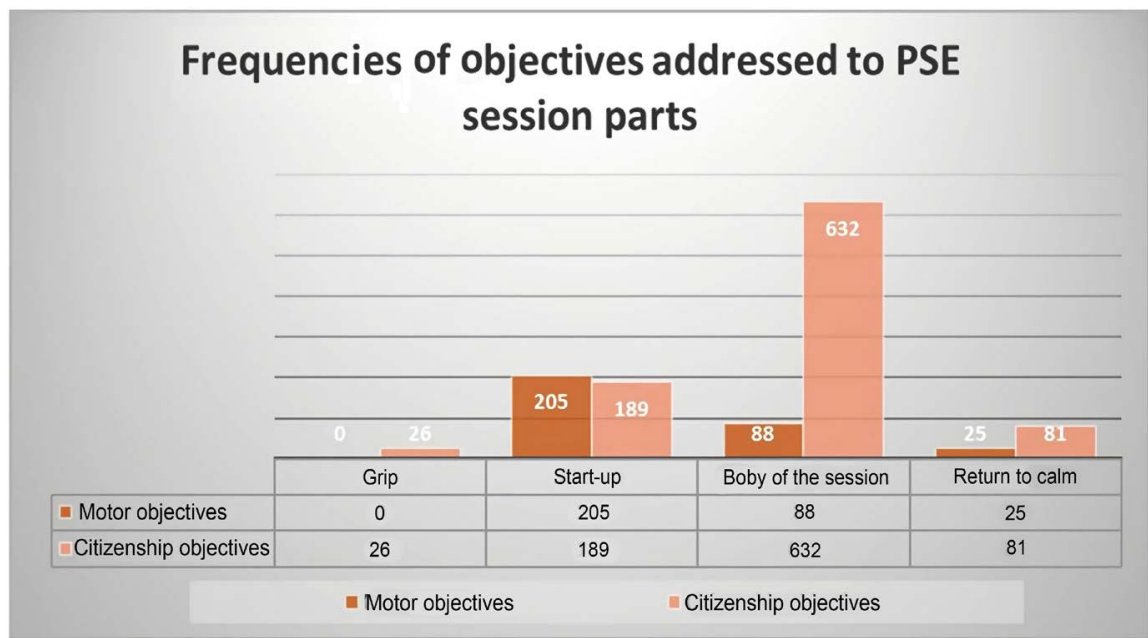

Figure 7. Frequencies of objectives addressed to PSE session parts.

Thus, the frequency of citizenship goals depends on the duration of the PSE session, the nature of the situation or the motor exercise practiced and the nature of the teacher's intervention.

\section{Discussion \& Conclusion}

The analysis of the data indicates that the treatment of civic values depends on the mode of their treatment (explicit or implicit). PSE teachers are responsible for the explicit treatment of civic values. Citizen values are conveyed implicitly through PSA. The treatment of civic values depends on the part of PSE session and its duration. Our results show that PSE is a favorable environment for citizenship education through two complementary modes, on the one hand, by the practice of PSA, which are themselves responsible for civic values, and on the other hand by teaching practice, which translates them into acts. Our results corroborate with the work of many researchers (Audigier, 2007; Delignières, 2015; Feyfant, 2010; Galichet, 2002; Heimberg, 2007) who argue in favor of the idea that citizenship education is not limited to the learning and transmission of theoretical ideas, but rather, it must be consolidated by practices in action to succeed life together.

The results of our research revolve around two points: The Official Texts governing the PSE, the didactic practice of the teachers of PSE and the evaluation reports pedagogy to convey two types of objectives, one with motor aim, and the others of citizenship but at different percentages. During a PSE lesson, civic values are conveyed implicitly through the didactical situations and the activity taught and explicitly by the didactic interventions of the PSE teacher.

$\mathrm{PE}$ is a school discipline promoting citizenship education in two complementary modes, on the one hand, by the implicit mode of PSA practice, the latter implicitly carries citizen values, on the other hand an explicit mode, whose teacher is responsible, thus translating citizen values into action.

This research can be supplemented by a direct interview with the teachers be- 
fore the session and a self-confrontation interview with the visualization of the video of the session in order to be able to compare the teachers' beliefs with their achievements on the ground as regards the treatment of civic values.

\section{Recommendations}

We recommend that the content be supported by educational and socializing motor learning situations, and that professional training of PSE teachers be started as soon as they enter the university so as to schedule teacher training, granting as many importance to the educational and social fields and to focus during the days and pedagogical inspections on citizen interventions.

\section{Conflicts of Interest}

The authors declare no conflicts of interest regarding the publication of this paper.

\section{References}

Andrew, M. M., Tessier, C., \& Bourgeault, G. (1997). L'éducation à la citoyenneté en milieu scolaire au Canada, aux Etats-Unis et en France: Des orientations aux réalisations. Revue française de pédagogie, 121, 57-77. https://doi.org/10.3406/rfp.1997.1146

Audigier, F. (2007). L'éducation à la citoyenneté dans ses contradictions. Revue internationale d'éducation de Sèvres: L'élève, futur citoyen, 44, 25-34. https://doi.org/10.4000/ries.125

Delignières, D. (1999). Intentions éducatives et apprentissages effectifs en EPS. In Conférence invitée au Congrès International de I'AIESEP 1999. Besançon: Sport-Performance-Santé.

Delignières, D. (2015). L'Education Physique et Sportive et l'éducation à la citoyenneté. In C. Piard, L. Bosquet, \& A. Junques (Eds.), Le sport au services de l'éducation et des connaissances. Paris: EPS.

Dugas, É. (2002). Éducation physique et éducation informelle à l'école. Éducation et Sociétés, 10, 21-34. https://doi.org/10.3917/es.010.0021

Feyfant, A. (2010). L'éducation à la citoyenneté. INRP: Institut National de Recherche Pédagogique, 57, 1-15.

Galichet, F. (2002). La citoyenneté comme pédagogie: Réflexions sur l'éducation à la citoyenneté. Revue des sciences de l'éducation, 28, 105-124.

https://doi.org/10.7202/007151ar

Heimberg, C. (2007). Portée et limites de l'éducation à la citoyenneté démocratique. In Education en contextes pluriculturels: La recherche entre bilan et prospective (pp. 1-9). Genève: Archive ouverte UNIGE. 